\title{
Enhancing the dynamic temperature stability of epoxy with graphene oxide
}

\author{
Yu Qiao ${ }^{\mathrm{a}, \mathrm{b}}$, Pengfei Wang ${ }^{\mathrm{a}, *}, \mathrm{Xiao}_{\mathrm{Xue}}^{\mathrm{a}}$, Mao Liuc ${ }^{\mathrm{c}}$, Songlin $\mathrm{Xu}^{\mathrm{a}, * *}$ \\ ${ }^{\text {a }}$ CAS Key Laboratory of Mechanical Behavior and Design of Materials, Department of Modern Mechanics, University of Science and Technology of China, Hefei, 230027, \\ China \\ ${ }^{\mathrm{b}}$ State Key Laboratory of Nonlinear Mechanics, Institute of Mechanics, Chinese Academy of Sciences, Beijing, 100190, China \\ ${ }^{\mathrm{c}}$ Faculty of Science, Engineering and Technology, Swinburne University of Technology, Hawthorn, Vic, 3122, Australia
}

\section{A R T I C L E I N F O}

\section{Keywords:}

Dynamic behavior

Temperature effect

Strain rate

Hopkinson bar

Graphene oxide

\begin{abstract}
A B S T R A C T
Temperature-dependence mechanism of composites under dynamic loadings is essential for designing the aircraft with harsh operation environment. In this work, the dynamic compression mechanical behavior of graphene oxide modified epoxy (GO-epoxy) was systematically investigated over the temperature range from $298 \mathrm{~K}$ to $423 \mathrm{~K}$ under the loading strain rate of $5000 \mathrm{~s}^{-1}$. The results indicate that the compression properties of GOepoxy are sensitive to the strain rate and temperature. The yield strength of pure epoxy and GO-epoxy under dynamic loading were twice those under quasi-static loading. The strength gradually decreases as the temperature increases, but the temperature stability of GO-epoxy is significantly improved compared to the pure epoxy. The addition of GO helps to inhibit the movement of the molecular chain, suppress the stress softening, prevent the evolution of the micro-cracks and then increase the thermal stability of epoxy. The high speed photograph combined with the digital image correction (DIC) method indicates that GO improves the impact resistance of epoxy at different temperatures and the interfacial interactions contribute to this strengthening mechanism. A modified temperature and rate-dependent empirical constitutive model was developed to describe the dynamic behavior of pure/GO epoxy. The fracture morphologies show the difference failure modes between the GO-epoxy and the pure epoxy. This work on the temperature dependent dynamic behavior of GO modified epoxy could provide guidance for understanding the dynamic strengthening and thermal softening behaviors of nano-reinforcing composites.
\end{abstract}

\section{Introduction}

Fiber metal laminates (FMLs) have been widely used in airplanes and vehicles, such as Boeing 787 and BMW-i3 (Payeganeh et al., 2010; Treutenaere et al., 2017), owing to their excellent specific strength and modulus (Acar et al., 2018; Ávila et al., 2011; Tian et al., 2019). In the fabrication process of FMLs, the epoxy matrix acts as the adhesive for binding different layers, so the mechanical properties of FMLs largely depend on epoxy matrix. The harsh application environments and temperature rise caused by friction of high-speed aircraft put forward higher requirements for the dynamic reliability and thermal stability of epoxies (Liu et al., 2018; Zhang et al., 2020). Therefrom, it is very important to improve the environmental adaptability of epoxy performance.

Recently, graphene oxide (GO), carbon nanofibers (CNF) and other nanofillers have attracted wide attention in strengthening the mechanical behavior of matrix (Adak et al., 2018; Sheinerman et al.,
2019). As a two-dimensional nanomaterial, the GO has received great enthusiasm in electrical and mechanical fields owing to its excellent specific strength/modulus, electrical conductivity and thermal stability (Chabot et al., 2014; Guo et al., 2019; Xia et al., 2017). At the microscale, the strength and toughness of GO bilayers were about $23.5 \mathrm{GPa}$ and $\sim 1.71 \times 10^{-18} \mathrm{~J} / \mathrm{nm}^{3}$ (Cui et al., 2018), respectively. The graphene layers had also been proved to be an excellent anti-penetration 2Dmaterial in preventing the high velocity micro-bullet impact (Fu et al., 2014). The ballistic resistance was predicted by a membrane stretching analysis, which enabled us to present an outlook on the ballistic resistance potential of graphene composites (O'Masta et al., 2017). Additionally, GO has potential application in strengthening the epoxy's mechanical properties as a reinforcement phase. However, numerous works were focused on the quasi-static loading, which was not suitable to estimate the dynamic bearing capacity under high-speed collision. Chen et al. (2014) presented that the GO decorated glass fiber results in enhancing the mechanical interlocking between glass fibers and matrix.

\footnotetext{
* Corresponding author.

** Corresponding author.

E-mail addresses: pfwang5@ustc.edu.cn (P. Wang), slxu99@ustc.edu.cn (S. Xu).
} 
Wang et al. (2017) indicated that the interlayer crack growth behavior of carbon fiber reinforced polymer (CFRP) could be tuned from instantaneous unstable to continuous stable extension process while coating the poly-dopamine (PDA) and GO on the surface of carbon fiber fabric. Wan et al. (2014) also demonstrated that the GO-epoxy has better quasi-static mechanical properties and thermal stability. In order to meet the high speed/temperature operation situation of composite, the effects of temperature under dynamic loading need to be taken into consideration. Generally, the split Hopkinson pressure (SHPB) bar equipped with high temperature furnace was widely used to measure the dynamic behavior under different temperatures (Wang et al., 2014, 2015). Gómez et al. (Gómez-del Río and Rodríguez, 2012) studied the strain rate and temperature effects of pure epoxy (based on diglycidyl ether of bisphenol A), ranging from $0.0025 \mathrm{~s}^{-1}$ to $2500 \mathrm{~s}^{-1}$ and from room temperature to $100{ }^{\circ} \mathrm{C}$. Khan et al. (2017) investigated the stressstrain curves of epoxy-based foam over a wide range of strain rates $\left(10^{-4}-10^{3} \mathrm{~s}^{-1}\right)$ and temperatures $\left(-20-80{ }^{\circ} \mathrm{C}\right)$. However, it is still limited in uncovering the dynamic strengthening of GO-epoxy with the effect of temperature.

In order to withstand the harsh application environments of composites, GO was incorporated into epoxy for improving the impact resistant and temperature stability. The dynamic mechanical properties of GO-epoxy were systematically investigated from $298 \mathrm{~K}$ to $423 \mathrm{~K}$ by SHPB devices equipment with a visualized high temperature furnace, and the strain rate and temperature effects of composites were obtained. Additionally, the strain field and fracture morphology of different specimen were contrasted by the digital image correlation (DIC) and scanning electron morphology (SEM) respectively, to analyze the influence of the interfacial interactions on fracture behaviors of GOepoxy.

\section{Materials and method}

\subsection{Preparation of GO-epoxy}

Graphene oxide (GO, TNGO-3, greater than $95 \%$ in $98 \mathrm{wt} \%$, less than $1.5 \mathrm{wt} \%$ in AHS, $1-5 \mu \mathrm{m}$ in diameter), in Fig. 1(a), were purchased from Time Nano Inc. (CHN). The epoxy (Epolam 5015) and amine curing agent 5015 were purchased from Axson, Inc. (USA). The GO $(0.15 \mathrm{~g})$ was directly dispersed into the epoxy $(7.58 \mathrm{~g})$. In Fig. 1(b), the paste-like mixture was then dispersed by ultrasonic (Model: DELTA $\mathrm{DC} 150 \mathrm{H})$ for $180 \mathrm{~min}$, meanwhile, the mixture was manually mixed and cooled with an ice-water bath for 2 min every $20 \mathrm{~min}$. Then, the amine curing agent $(2.27 \mathrm{~g}$, the weight ratio of curing agent and epoxy resin was 0.3 ) was added into GO/epoxy mixture. Subsequently, the mixture was manually stirred for $10 \mathrm{~min}$ and degassed for $20 \mathrm{~min}$ in a vacuum oven (Model: GONGXING D2F-6020AF) at ambient temperature. After that, the degassed GO/epoxy mixture was injected into a home-made silicone mold with $\phi 8 \mathrm{~mm}$ cylindrical hole array, and was degassed in a vacuum oven for $20 \mathrm{~min}$. Finally, the GO/epoxy mixture was cured at $80{ }^{\circ} \mathrm{C}$ for $24 \mathrm{~h}$, and the GO-epoxy was cut into several specimens with the same size of $\phi 8 \times 5 \mathrm{~mm}$ for both quasi-static and dynamic tests as shown in Fig. 1(c). Meanwhile, the pure epoxy was prepared as a comparison.

\subsection{Methods}

In this study, the SHPB device with the diameter of $\phi 14.5 \mathrm{~mm}$ was used to obtain the dynamic properties of epoxy composites (Fig. 1 (d)). The bars and projectile of the SHPB device are made of steel with the elastic modulus and the density of $210 \mathrm{GPa}$ and $7.8 \mathrm{~g} / \mathrm{cm}^{3}$, respectively. In this experiment, square rubber with the side of $1 \mathrm{~mm}$ and the thickness of $1 \mathrm{~mm}$ was used as pulse shaper. The projectile with the length of $300 \mathrm{~mm}$ was fired at the impact velocity of $30-33 \mathrm{~m} / \mathrm{s}$, and the loading strain rates were about $5000 \mathrm{~s}^{-1}$ through controlling the impact velocity. A high-temperature furnace having an observation window was implemented to heat the GO-epoxy to 333K, 363K, 393K and $423 \mathrm{~K}$. The strain gauges were pasted on the incident and transmission bars for measuring the time-history signals. The typical original waveform is shown in Fig. 1 (e), and the stress-strain curves were calculated by three-waves method (Chen and Song, 2011; Ye et al., 2019). In addition, the high-speed deformation process was recorded by a Phantom V12 camera, and the shooting speed was 100,000 frames per second. It is noteworthy that the specimen and bars were heated together in the high temperature furnace equipment. Consequently, the measured stress waves were affected by temperature when passing (a)

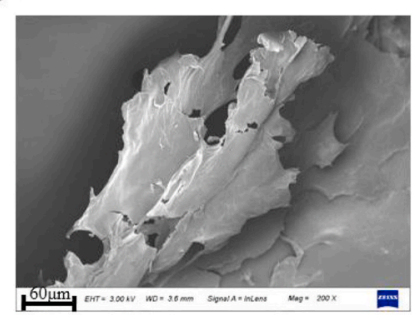

(d)

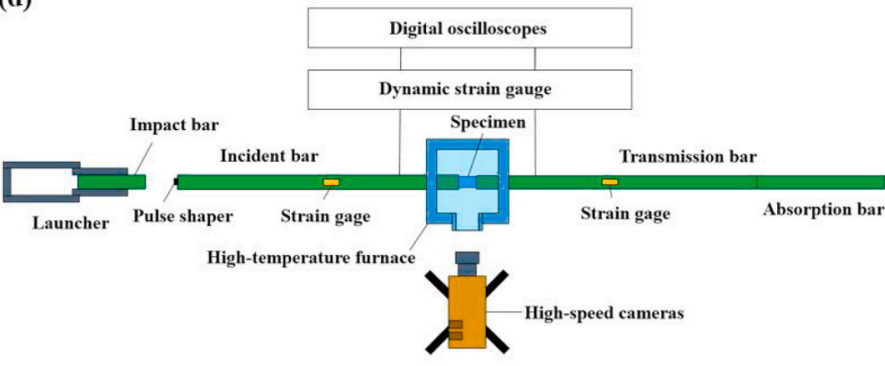

(b)
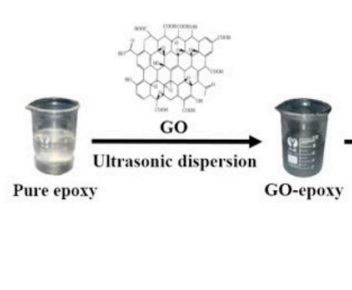

Degassin Curing in th
incision ing in th
incision

(c)

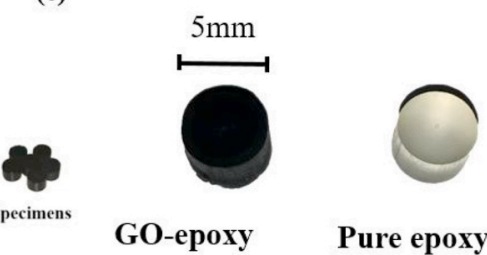

(e)

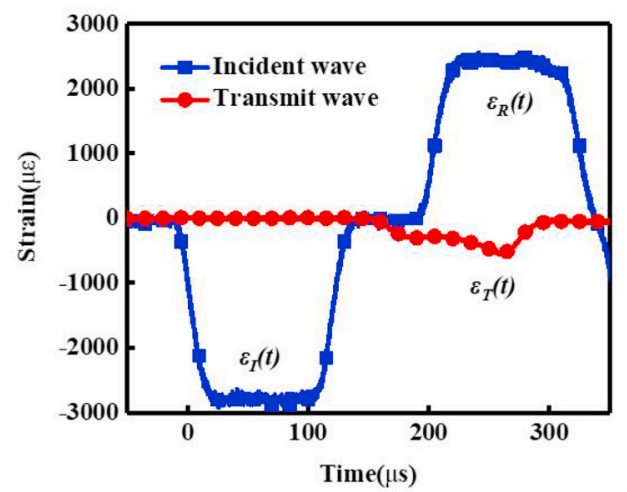

Fig. 1. (a) The morphology of graphene oxide, (b) preparation process of GO-epoxy, (c) specimens of GO-epoxy and pure epoxy, (d) schematic of visualized hightemperature SHPB device, (e) original waveform of SHPB test. 
through the heated parts of the bars. In this experiment, the maximum temperature in the high temperature furnace is $423 \mathrm{~K}$, which has insignificantly effects on the steel bar. Moreover, the simple method proposed by Zhou et al. can be used to modify the temperature effects of this experiment (Zhou et al., 2010). The Material Testing System (MTS 809) was used for quasi-static experiments $\left(\dot{\varepsilon}=0.01 \mathrm{~s}^{-1}\right)$. The XL30 ESEM-TMP Environmental Scanning Electron Microscope (SEM) scanning was conducted for the microscopic analysis.

The establishment of constitutive equations describing the mechanical behavior of epoxy is generally based on the ZWT model, which is a nonlinear viscoelastic constitutive model, consisting of a nonlinear spring and two paralleled Maxwell units. This model describes the mechanical behavior of polymer as a function of strain rate and strain. The abbreviated form of the ZWT model can be expressed as Eq. (1):

$\sigma=f_{e}(\varepsilon)+\sigma_{1}(\varepsilon, \dot{\varepsilon})+\sigma_{2}(\varepsilon, \dot{\varepsilon})$

where $f_{e}(\varepsilon)$ is nonlinear elastic term; $\sigma_{1}(\varepsilon, \dot{\varepsilon})$ is the integral term describing viscoelastic response at lower strain rates $\left(10^{-4}-10^{-1} \mathrm{~s}^{-1}\right)$ and $\sigma_{2}(\varepsilon, \dot{\varepsilon})$ represents the integral term at higher strain rates $\left(10^{1}-10^{3}\right.$ $\mathrm{s}^{-1}$ ) (Wang et al., 2010).

\section{Results and analysis}

\subsection{Strain rate effect and stress drop}

The strain rate effect as one of the important factors is particularly critical in analyzing material's dynamic mechanical response. To investigate the strain rate sensitivity behavior of epoxy, the dynamic and quasi-static compression performance of epoxy-based composites were investigated. Fig. 2(a) shows that the introducing of GO filler was effective in improving the stress of epoxy under both the quasi-static and dynamic loadings. The stress-strain curves of epoxy have some typical characteristics. Firstly, the stress increase linearly at the initial stage of deformation. Due to the viscoelastic properties of epoxy, the stressstrain curve exhibits nonlinear behavior when the stress value reaches near the yield stress. After yielding, the material soften and the stress gradually decrease (Arash et al., 2019). As the increasing of the strain, the hardening rate of the material change from negative to positive and the stress-strain curves present increasing hardening trends. So far, there are a peak near the yield point and a softening trough on the stress-strain curves. In this work, the value of the yield stress was taken from the extreme value of the yield peak in stress-strain curves. Under quasi-static compression loading, the yield strengths of pure epoxy and GO-epoxy were $93 \mathrm{MPa}$ and $97 \mathrm{MPa}$, respectively. Moreover, under dynamic loading, the yield strengths of pure epoxy and GO-epoxy increased to $165 \mathrm{MPa}$ and $188 \mathrm{MPa}$, respectively. As strain rate increased

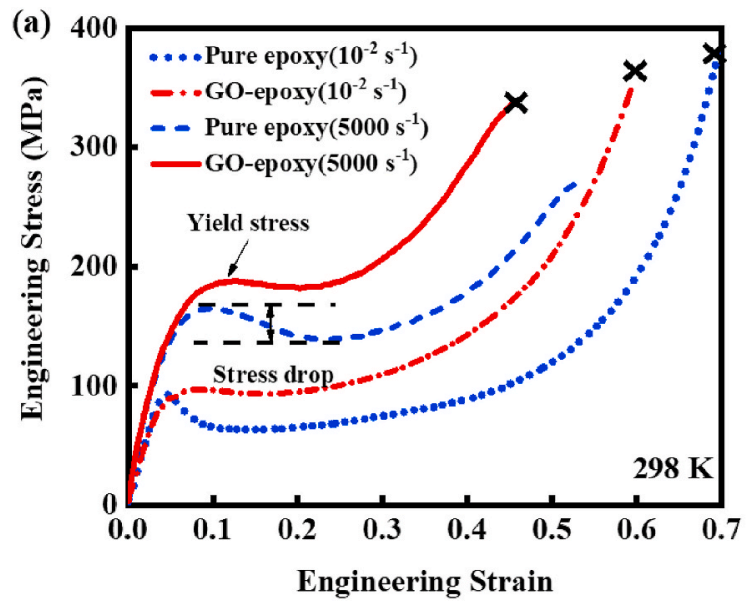

from $10^{-2} \mathrm{~s}^{-1}$ to $5000 \mathrm{~s}^{-1}$, the yield stresses of pure and GO-epoxy increased by $77 \%$ and $94 \%$, respectively. The yield stresses of pure epoxy and GO-epoxy under quasi-static compression are close. However, GO-epoxy show excellent dynamic yield performance. This indicates that GO-epoxy is more sensitive to strain rate than pure epoxy.

In the compression tests of this work, the stress-strain curves were recorded until the specimens crushed. In the experiments, some longitudinal cracks appeared in the specimen, and the cracks eventually penetrated the specimen and divided it into several parts. The locations of the break are marked with black crosses in Fig. 2(a). Under the quasistatic loading, the failure strain of GO-epoxy was about 0.60 , which was lower than that of pure epoxy (0.70). In the dynamic loading process, the pure epoxy was not crushed under the first loading wave, and the maximum strain was 0.53 . However, during the first loading process, the GO epoxy was crushed under a strain of 0.46 . The strain-energy densities of two materials are obtained by integrating the stress-strain curves in Fig. 2(b), and the strain energy density under both quasi-static and dynamic loads has been improved with the addition of GO. This result indicates that the incorporation of GO was beneficial to enhance the energy absorption performance of epoxy.

It is worth noting in Fig. 2(a) that GO played an important role in eliminating the stress softening process after the yielding. To better describe this stress softening properties, as shown in Fig. 2(a), we define the stress drop $\Delta \sigma$ as the difference between the minimum value in the softening trough and the yield stress value. And a dimensionless quantity named stress drop coefficient $\eta$ is introduced as $\eta=\Delta \sigma / \sigma_{y}$, where $\sigma_{y}$ is the yield stress (Wang et al., 2014). The stress drop coefficient of pure epoxy significantly decreased from 0.32 to 0.16 as the loading rate increased. However, the GO-epoxy shown insignificant stress drop, where the quasi-static and dynamic stress drop coefficients were 0.04 and 0.03 , respectively. This indicates that the addition of GO significantly inhibited the softening effect of epoxy. In addition, the high loading strain rate also reduced the softening of epoxy.

The physical mechanism of stress softening might be related to the interactions of polymer chains. Polymers usually have characteristically entangled platforms where stress is relaxed by chain creep or branch contraction (Kapnistos et al., 2008). In the dynamic loading state, the sudden loss of special degrees of freedom enhances the deformation resistance of the polymer chains (Mulliken and Boyce, 2006). The stress drop under dynamic loading is also inhibited owing to the limited chains' motion. The strain-softening degree intends to be increased with the physical aging time, and the mechanical pre-conditioning or quenching process could reduce this phenomenon (Dépinoy et al., 2019). The influence of GO on the polymer chains is discussed in Section 4.2.

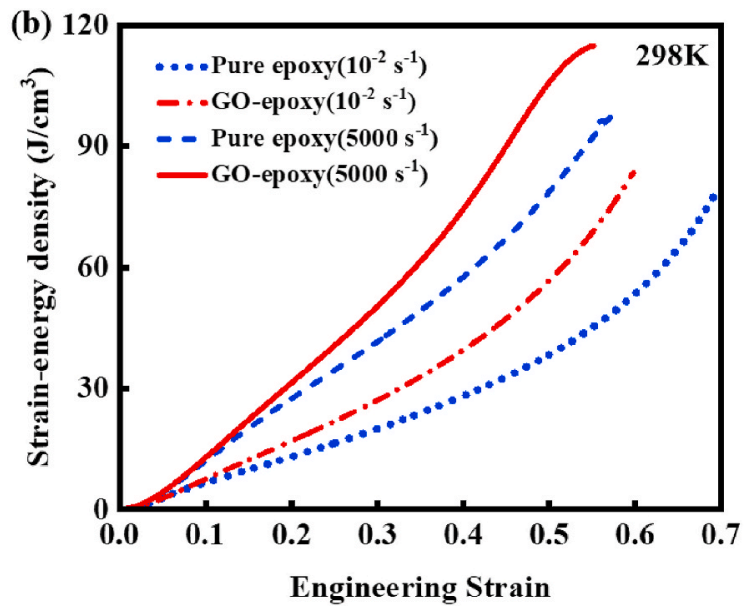

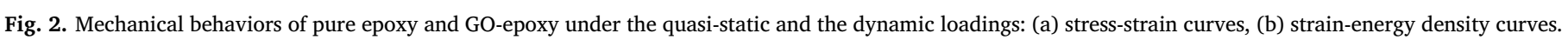


Table 1

Yield stress and stress drop under different temperatures $\left(5000 \mathrm{~s}^{-1}\right)$.

\begin{tabular}{lllllll}
\hline $\begin{array}{l}E \\
\text { pure } \\
\text { epoxy } \\
(\mathrm{GPa})\end{array}$ & $\begin{array}{l}E \text { GO- } \\
\text { epoxy } \\
(\mathrm{GPa})\end{array}$ & $\begin{array}{l}\sigma_{y} \\
\text { pure epoxy } \\
\text { (MPa) }\end{array}$ & $\begin{array}{l}\sigma_{y} \\
\text { GO-epoxy } \\
(\mathrm{MPa})\end{array}$ & $\begin{array}{l}\eta \\
\text { pure } \\
\text { epoxy }\end{array}$ & $\begin{array}{l}\eta \\
\text { GO-epoxy }\end{array}$ \\
\hline $298 \mathrm{~K}$ & 4.59 & 4.95 & 165 & 188 & 0.16 & 0.03 \\
$333 \mathrm{~K}$ & 3.52 & 3.51 & 132 & 164 & 0.17 & 0.05 \\
$363 \mathrm{~K}$ & 2.46 & 3.15 & 93 & 139 & 0.09 & 0.03 \\
$393 \mathrm{~K}$ & 0.71 & 2.66 & 30 & 104 & - & 0.02 \\
$423 \mathrm{~K}$ & - & 1.08 & - & 50 & - & -
\end{tabular}

" _" in the table: unavailable.

\subsection{Temperature dependence of dynamic mechanical behavior}

The rising of ambient temperature induce the drastic motion of molecular chain, which is liable to produce the large plastic deformation and low flow stress. The elastic modulus $(E)$, yield stress $\left(\sigma_{y}\right)$ and stress drop coefficient $(\eta)$ of GO-epoxy and pure epoxy at different temperatures are listed in Table 1. And Fig. 3 (a) and (b) shows that the flow stress and elastic modulus gradually decreased as the temperature increases, but the GO-epoxy presented a higher stress than that of pure epoxy at all of the tested temperatures. The pure epoxy almost lost the load-bearing capacity at $423 \mathrm{~K}$, but the GO-epoxy still kept certain considerable strength. On the other hand, to quantify the dependence of flow stress on temperature, the stresses at strains of 0.25 and 0.4 were

(a)

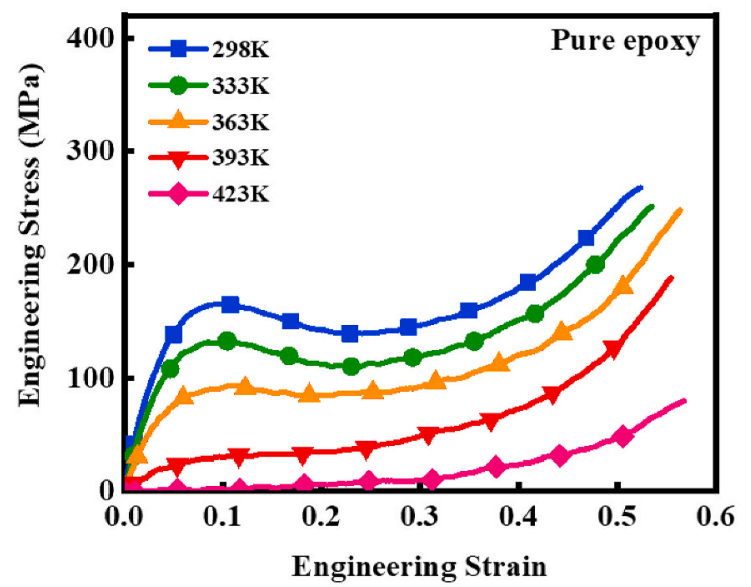

(c)

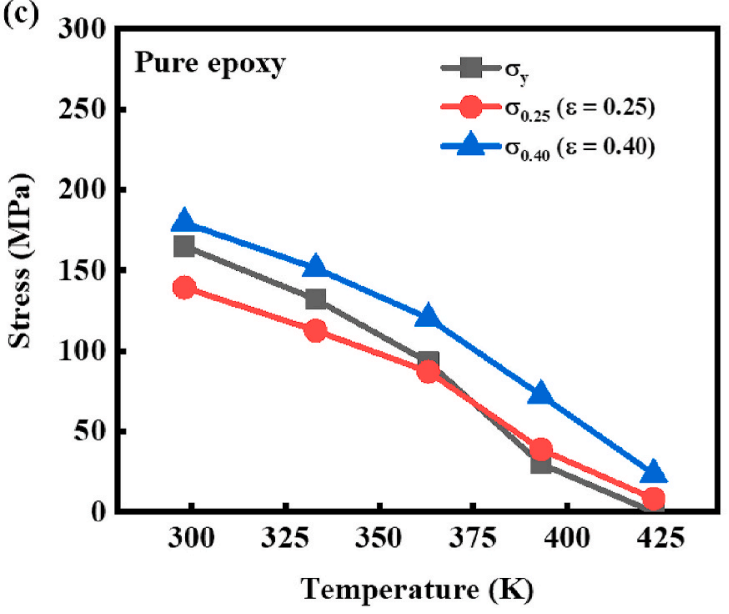

chosen to represent the flow stresses during the softening and hardening of epoxy, respectively. Fig. 3(c) and (d) shows the dependence of yield stress and flow stress $(\varepsilon=0.25$ and 0.4$)$ on temperature. As the temperature rose, the flow stress of pure epoxy gradually decreased meanwhile the stress drop disappeared. The addition of GO made the flow stress of epoxy soften more gently, and the hardening ability increase significantly. To describe the softening effect of epoxy at high temperatures, the parameter $\gamma=\sigma_{y} / \sigma_{y, 293 \mathrm{~K}}$ is determined by the yield stress ratio of ambient temperature to room temperature (293K). The Fig. 4 (a) shows the dependence of the $\sigma_{y} / \sigma_{y, 293 \mathrm{~K}}$ on temperature. At high temperature, the decrease in stress of GO-epoxy was significantly smaller than that of pure epoxy. In other words, GO-epoxy had a stronger ability to resist weakening effect as the temperature. This result indicates that the thermal stability of GO-epoxy is better than that of pure epoxy, and the stress drop of these epoxy specimens gradually decrease and eventually diminishe as the temperature increases. The epoxy change from glassy state to rubbery state and the rigidity of the polymer chain is reduced rapidly as the temperature increases. At high temperatures, the molecular chains rigidity of pure epoxy decreases significantly. The stress drop is the process of materials stress relaxation after yielding. Therefore, the substantial reduction in the yield stress of pure epoxy results in the stress drop at high temperatures no longer being noticeable. (Xiao and Nguyen, 2015). Fig. 4(b) also shows the superior strain-energy density of GO-epoxy under different temperature in comparison with that of pure epoxy. Among them, the strain energy density of pure epoxy at $298 \mathrm{~K}$ and $363 \mathrm{~K}$ were similar to GO-epoxy at (b)

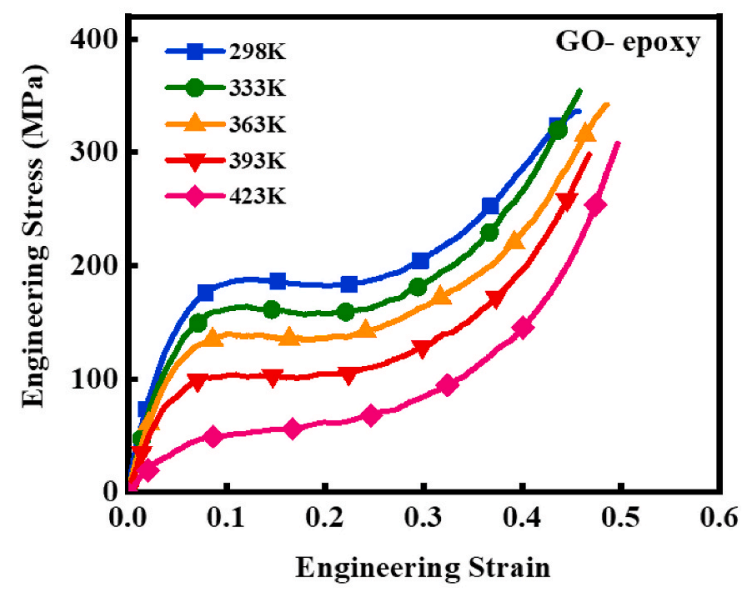

(d)

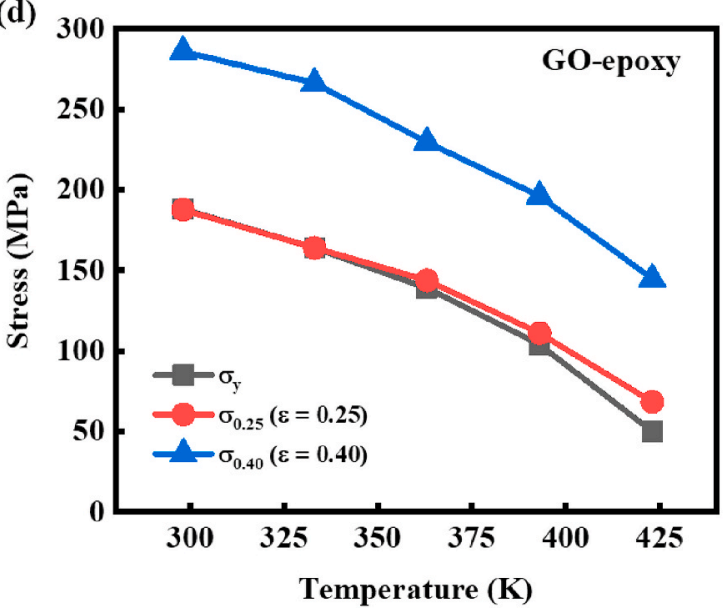

Fig. 3. Temperature dependences of (a) neat-epoxy and (b) GO-epoxy under a strain rate of $5000\left(\mathrm{~s}^{-1}\right)$, and comparison of stress as a function of temperature for (c) pure epoxy and (d) GO-epoxy. 
(a)

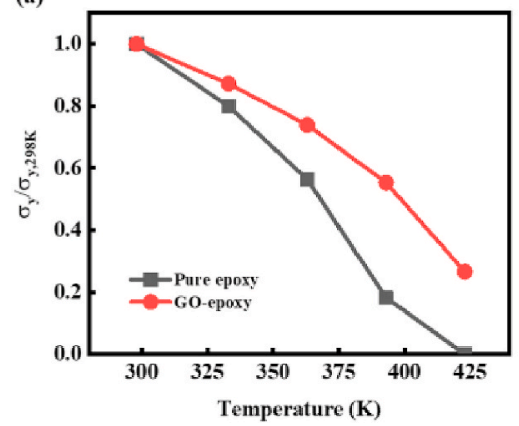

(b)

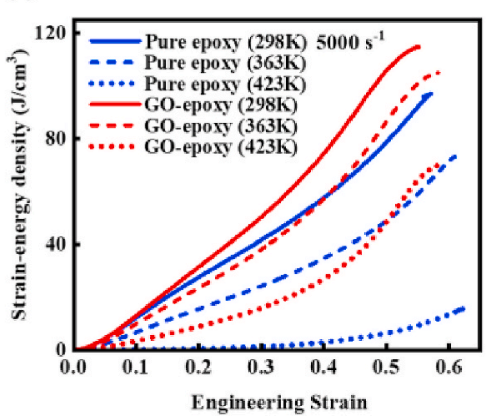

(c)

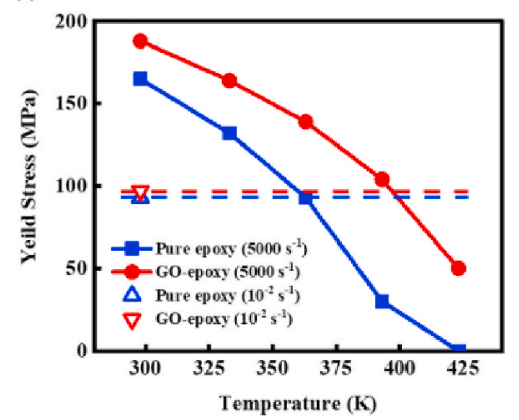

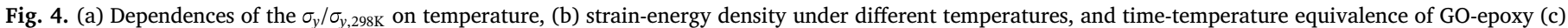
yield stress and (d) stress-strain curves.

$363 \mathrm{~K}$ and 423K, respectively. In other words, the remarkable strengthening effect of GO is equivalent to lowering the ambient temperature of $60-65 \mathrm{~K}$.

As all known, the time-temperature equivalence is common in polymers, which means that the softening effect caused by increasing temperature can be offset by the strengthening effect caused by increasing the strain rate. (Liao et al., 2019). The reason is that the temperature effect and strain rate effect in polymers correspond to similar molecular motion mechanisms. In the quasi-static room temperature test, the yield stresses of pure epoxy and GO-epoxy were similar. But in the dynamic temperature test, the yield stresses of pure epoxy and GO-epoxy were significantly different. It is certain that the addition of GO affected the time-temperature equivalent of epoxy. In order to describe the above in detail, the Fig. 4(c) shows the yield stress of all tests at different temperatures. The quasi-static yield stresses of pure epoxy and GO-epoxy at room temperature were approximately equivalent to the dynamic yield stress at $363 \mathrm{~K}$ and $393 \mathrm{~K}$, respectively. As reported by Williamson et al. (2008), the time-temperature equivalence can be described by a linear relationship.

$\frac{\Delta \log \dot{\varepsilon}}{\Delta T}=\mathrm{c}$

where the $\mathrm{c}$ is the sensitivity of time-temperature. When the strain rate increases by one order of magnitude, the effect is the same as decreasing the temperature of epoxy by $1 / \mathrm{cK}$. Based on Eq. (2), the $\mathrm{c}$ of pure epoxy and GO-epoxy are 0.088 and 0.060 , respectively. In other words, when the strain rate rises by one order of magnitude, the effect is equivalent to the ambient temperature of pure epoxy and GO-epoxy falling by $11.4 \mathrm{~K}$ and $16.7 \mathrm{~K}$, respectively. On the other hand, when the ambient temperature is increased by $50 \mathrm{~K}$, the effect is equivalent to the logarithm of the loading strain rate $(\log \dot{\varepsilon})$ of pure epoxy and GO-epoxy decreased by 4.38 and 3.00 , respectively. This means that the temperature equivalent strain rates of pure epoxy and GO-epoxy differ by an order of magnitude. According to the above analysis, the effect of GO on the time-temperature equivalence of epoxy also indicates that the addition of GO enhanced the strain rate sensitivity of epoxy. In addition, the GO also suppressed the high temperature softening effect of epoxy.

\subsection{Dynamic deformation process}

High speed camera was utilized to observe the dynamic process under the same impact velocity but with different temperatures. Fig. 5 show the dynamic deformation process and the longitudinal compression strain field of pure epoxy and GO-epoxy under $298 \mathrm{~K}$ and $393 \mathrm{~K}$. The deformation fields of pure epoxy and GO-epoxy are relatively uniform, and the high-speed photography also show the rare surface cracks of epoxy. In order to reflect the deformation details of epoxy, the average value of each strain field in Fig. 5 is used to draw the straintime curves at different temperatures (Fig. 6(a) and (b)). The strain value of pure epoxy and GO-epoxy increased as the temperature increases, which indicates that the high temperature environment softened epoxy. At $298 \mathrm{~K}$, the strain fields between pure epoxy and GOepoxy were very similar, and their average value at $70 \mu$ s are 0.259 and 0.260 , respectively. As the temperature rose, the deformation rate of pure epoxy rose significantly, especially in the first $20 \mu \mathrm{s}$. However, the deformation of GO-epoxy in the first $20 \mu$ s was s almost the same at different temperatures. At $70 \mu \mathrm{s}$, the average strain of pure epoxy and GO-epoxy at 393K are 0.321 and 0.285 respectively, which indicates that the addition of GO improved the impact resistance of epoxy at high temperatures. In addition, Fig. 6(c) illustrates that the strain-time curve calculated by the DIC method is consistent with the experimental result.

The number density distributions of strain field (Zhou et al., 2018) were analyzed to characterize the transverse tensile strain field and its uniformity of the specimen's surface. Firstly, the strain value calculated by DIC was equally divided into 100 parts, and then the number of elements whose strain values belong to each part are counted. The number density is the result of dividing the number of elements by the length of part. Fig. 7 shows the transverse tensile strain distributions of pure epoxy and GO-epoxy at $393 \mathrm{~K}$ were greater than those at $298 \mathrm{~K}$. And the average value of the strain field at each moment is marked on the Fig. 7. Transverse strain values were concentrated at 0 while the specimens have not yet begun to deform at the initial time $(0 \mu \mathrm{s})$. The transverse strain value gradually increased and the transverse strain distribution became wider as the loading time increased, but few elements presented relatively lower transverse strain values due to the symmetrical lateral deformation near the axis of symmetry. Moreover, the average transverse strain of GO-epoxy at each stage was lower than pure epoxy at room temperature. And at 393K, the transverse strain values of GO epoxy and pure epoxy were close. the addition of GO has not led to the transverse strain field distribution of the epoxy from single peak to other types. In other words, the GO enhanced strength and reduced plasticity of epoxy, but its effect on plasticity was limited. This effect did not change the pattern of deformation and failure of epoxy in macro.

\section{Discussions}

\subsection{Modified ZWT constitutive model}

To describe the dynamic behavior of epoxy under different temperatures, a modified constitutive equation based on the ZWT model (Wang et al., 2010) was established.

The detail of ZWT model is expressed as Eq. (3):

$\sigma=E_{0} \varepsilon+\alpha \varepsilon^{2}+\beta \varepsilon^{3}+E_{1} \int_{0}^{t} \dot{\varepsilon} \exp \left(-\frac{t-\tau}{\theta_{1}}\right) \mathrm{d} \tau+E_{2} \int_{0}^{t} \dot{\varepsilon} \exp \left(-\frac{t-\tau}{\theta_{2}}\right) \mathrm{d} \tau$

where $E_{0}$ is the initial elastic modulus, and $\alpha$ and $\beta$ are the material parameters of the multiple integral model(Green and Rivlin, 1957; 

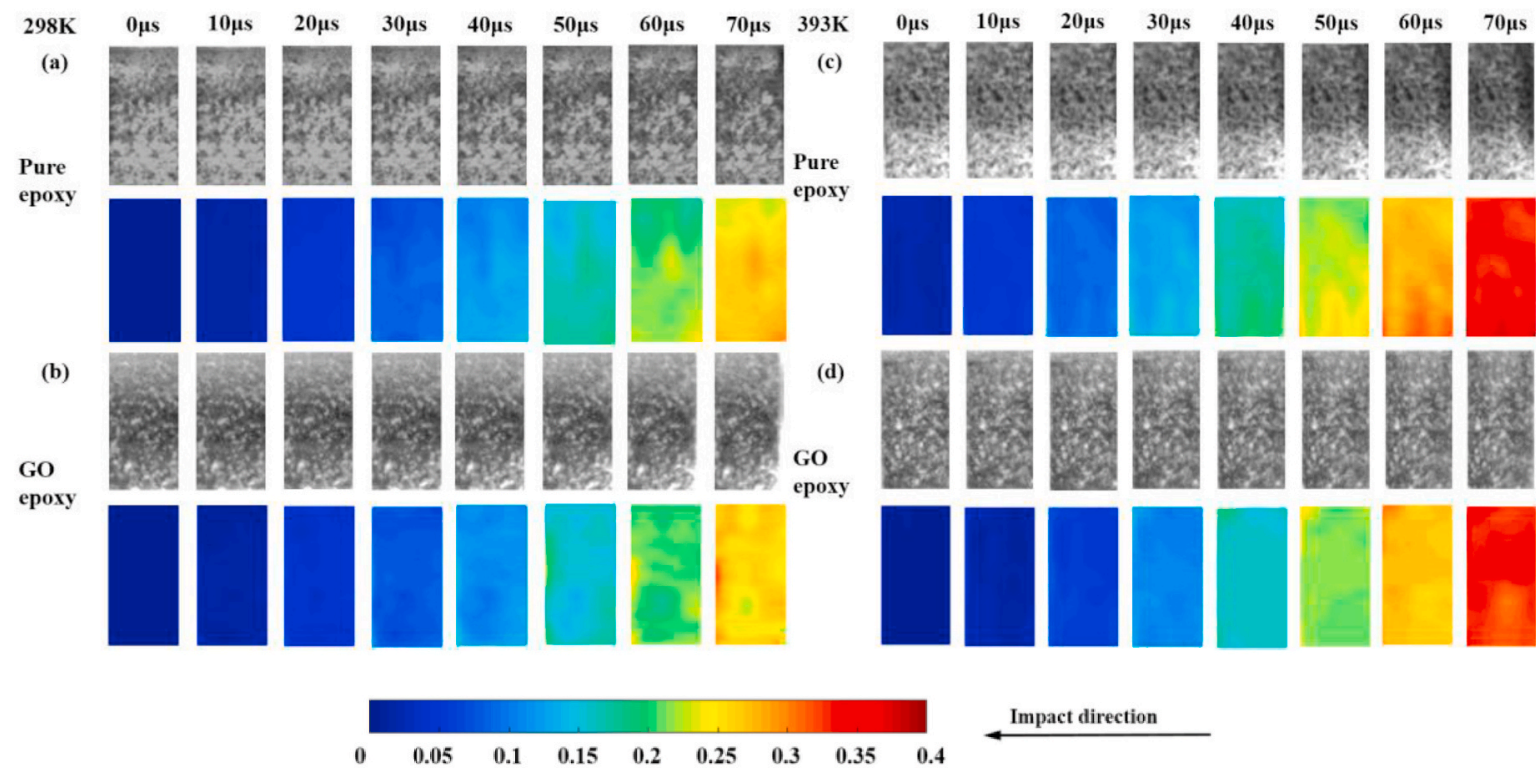

Fig. 5. Dynamic deformation process $(31 \mathrm{~m} / \mathrm{s})$ and longitudinal compression strain field calculated by DIC method of pure epoxy and GO-epoxy under different temperature (a) pure epoxy, 298K; (b) GO-epoxy, 298K; (c) pure epoxy, 393K; (d) GO-epoxy, 393K.

Ward and Pinnock, 1966). $E_{1}$ and $E_{2}$ are elastic constant of Maxwell unit at lower and higher strain rates, respectively. $\theta_{1}$ and $\theta_{2}$ are relaxation time of Maxwell unit at these two situations. If we only take the dynamic situation into consideration (Gao and Li, 2016), this model could be simplified as Eq. (4):

$\sigma=E_{0} \varepsilon+\alpha \varepsilon^{2}+\beta \varepsilon^{3}+E_{1} \int_{0}^{t} \dot{\varepsilon} \exp \left(-\frac{t-\tau}{\theta}\right) \mathrm{d} \tau$

where $E_{1}$ and $\theta$ are elastic constant and relaxation time of Maxwell unit at high strain rate, respectively. In this experiment, the strain rate is almost constant value under dynamic loading, and thus the Eq. (4) can be simplified to Eq. (5).

$\sigma=E_{0} \varepsilon+\alpha \varepsilon^{2}+\beta \varepsilon^{3}+E_{1} \theta \dot{\varepsilon}\left[1-\exp \left(-\frac{\varepsilon}{\theta \dot{\varepsilon}}\right)\right]$

Eq. (5) could be further modified as shown in Eq. (6) according to the empirical Johnson-Cook equation as a function of temperature (Song and Sanborn, 2018):

$\sigma=\left\{E_{0} \varepsilon+\alpha \varepsilon^{2}-\beta \varepsilon^{\lambda}+E_{1} \theta \dot{\varepsilon}\left[1-\exp \left(-\frac{\varepsilon}{\theta \dot{\varepsilon}}\right)\right]\right\}\left(1-T^{*}\right)^{m}$

$T^{*}=\frac{T-T_{0}}{T_{m}-T_{0}}$

where $T$ is the testing temperature, and $T_{0}$ and $T_{m}$ represent the room temperature and melting temperature, respectively. $m$ is the thermal softening exponent. Since $T_{m}$ is unknown, it is assumed that $m=1$. On the other hand, the ZWT model is the result of retaining the three terms of the multiple integral expansion, and neglecting the following higher order terms (Green and Rivlin, 1957). But such a constitutive equation cannot satisfy all situations. To fit the experimental results better, the triple integral term was converted into a fractional integral term with order to be determined. Therefore, the power index of the third nonlinear elastic term was modified as $\lambda$.

This empirical constitutive equation took the temperature and strain into consideration at a constant strain rate of 5000/s. The experimental data used for fitting was converted from the engineering stress-strain curve to the true stress-strain curve, and the large strain portions were ignored. As shown in Fig. 8(a) and (b), the tendency of Eq. (6) agrees well with the tested stress-strain curves of two materials under different temperatures. The material parameters in this model are detailed in the Table 2. Herein, $E_{0}$ represents the initial elastic modulus as the strain is close to zero, and this value of GO-epoxy is higher than that of pure epoxy. The $\alpha, \beta$ and $\lambda$ values of GO-epoxy were greater than that of pure epoxy. The increasing of the elastic constant $E_{1}$ and the relaxation time $\theta$ of GO-epoxy indicates that the GO improved the elasticity and reduced the viscosity of pure epoxy. Fig. 8(c) indicates that the fitted melting temperatures $T_{m}$ of pure epoxy and GO-epoxy were approximately $425 \mathrm{~K}$ and $469 \mathrm{~K}$, respectively. This is also consistent with the trend of experimental data, and it shows that thermal softening exponent $m=1$ is acceptable. Fig. 9(a) shows the initial elastic modulus $E_{0}$ ha a significant effect on the stress drop. On the other hand, in (a)

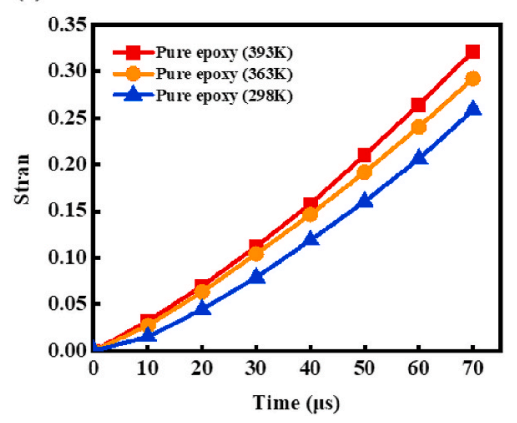

(b)

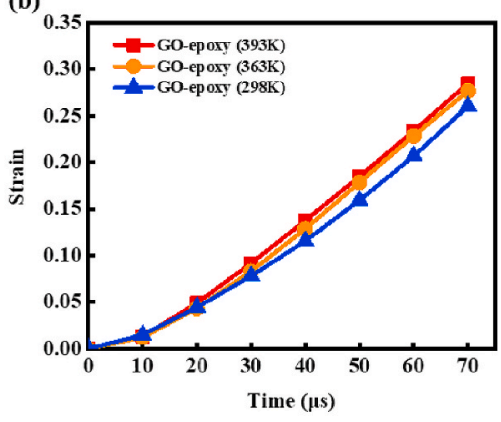

(c)

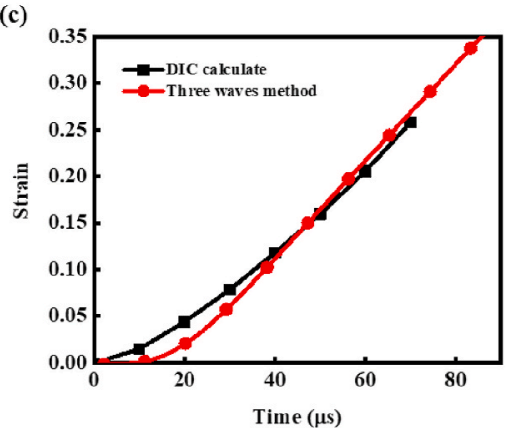

Fig. 6. The strain-time curves of (a) pure epoxy and (b) GO-epoxy (DIC), (c) DIC calculated strain and experiments results. 
(a) Pure epoxy (298K)

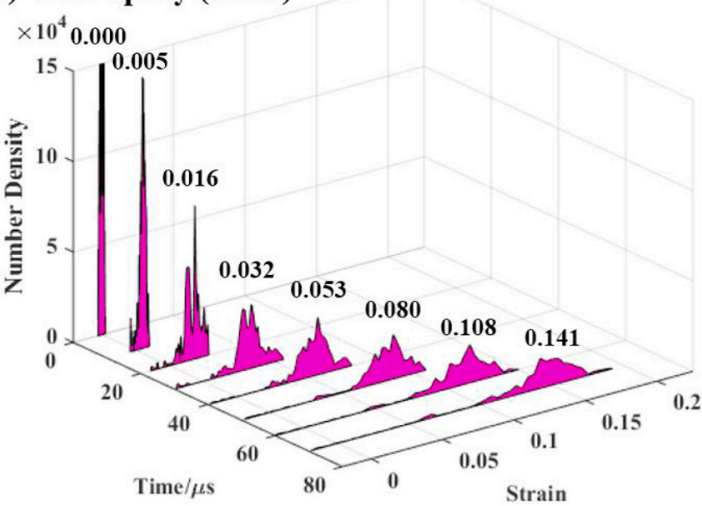

(c) Pure epoxy (393K)

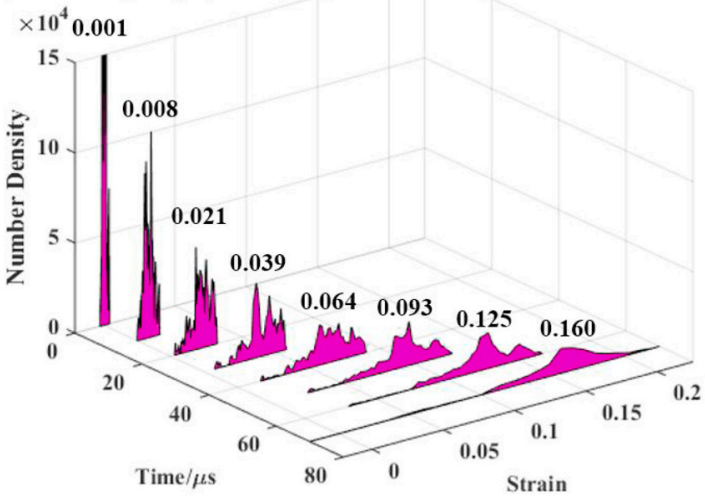

(b) GO-epoxy (298K)

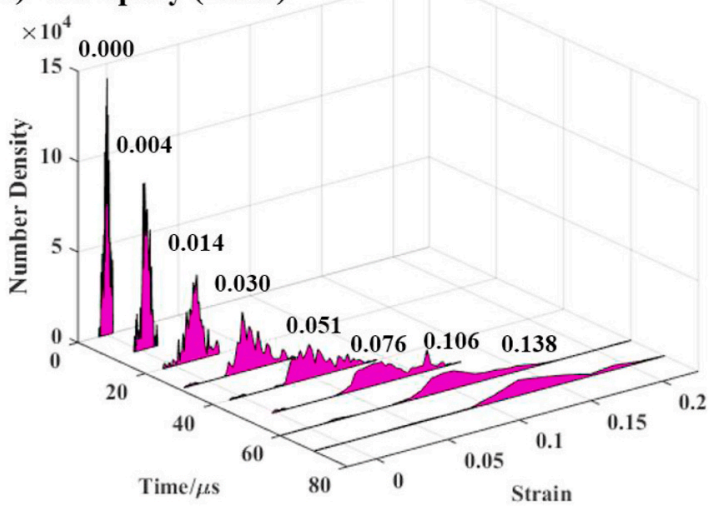

(d) GO-epoxy (393K)

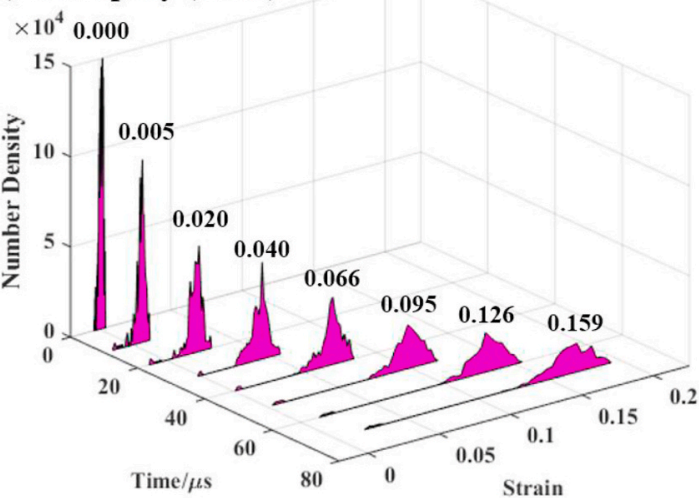

Fig. 7. Transverse strain field distribution under dynamic loading (31m/s) (a) pure epoxy, 298K; (b) GO-epoxy, 298K; (c) pure epoxy, 393K; (d) GO-epoxy, 393K.

Fig. 9(b), the stress-strain curves were almost parallel to each other for different elastic constants $E_{1}$. For polymeric materials, the initial elastic modulus $E_{0}$ and the elastic constant $E_{1}$ were related to the force required to uncoil and disentangle the molecular chains. GO as a strengthening phase limits the mobility of the molecular chains and hence raise the values of these parameters (Yan et al., 2015).

\subsection{Interface behavior and fracture morphologies}

Previous results confirmed that the addition of GO not only improved the mechanical properties, but also enhanced the temperature stability of neat-epoxy. Numerous interfaces have been introduced into the matrix while incorporating the GO filler. These interfaces play an important role in enhancing the mechanical property of epoxy. Superior interface friction or cohesive stress are beneficial in improving the strength of epoxy (Wang et al., 2019). The load transfer efficiency and the effective stiffness of the composite are sharply reduced owing to the agglomeration and interface defects with poor dispersion (Barai and Weng, 2011). There are many functional groups(such as C-O-C (epoxy ring), $\mathrm{C}-\mathrm{OH}$ (hydroxyl), $\mathrm{C}=\mathrm{C}$ (conjugated $\mathrm{sp} 2$ ) and $\mathrm{HO}-\mathrm{C}=\mathrm{O}$ (carboxylic) ) on the surface of GO (Pathak et al., 2016), which can interact with the functional groups on the epoxy resin. The evidence of hydrogen bonding between GO and epoxy was also observed by the decreasing of the carbonyl bond constant value in the Fourier Transform Infrared spectra (FTIR) (Gogoi et al., 2015). In this work, the addition of GO reduced the fluidity of epoxy through the interfacial interactions before the curing of epoxy, but the hydroxyl $(\mathrm{OH})$ and carboxyl $(\mathrm{COOH})$ groups on the surface of $\mathrm{GO}$ accelerated the curing reaction of the epoxy amine system (Wei et al., 2018). The GO acts as the bridge to connect the molecular chains and the prominent interface behavior, which results in more efficient load transfer within the material, favoring in increasing material's strength and reducing stress softening phenomenon. The excellent interfacial activity also makes GO have favorable dispersion in epoxy.

The microscopic morphology of the failure surface in this experiment provides more evidence for the interfacial action inside the materials. After the quasi-static loading, in Fig. 10(a), both the pure epoxy and GO-epoxy reveal the longitudinally collapsed and axial cracked. The molecular chain was compelled to reorientation along the external force direction, which generated the internal stress to balance the external force. The longitudinal cracks were appeared on the sides of specimens, and crushed eventually along the force direction. Due to the multiple loadings of the incident wave in the dynamic experiments, as shown in Fig. 10(b), the final recovered specimens were powders and longitudinally destroyed fragments.

The SEM images in Fig. 10 also show two primary features on the failure surface, namely linear traces and protrusions. The dominant mechanism is the development of main crack under the quasi-static loading, but numerous micro cracks generated around the main crack under the high-speed transient evolution process, which eventually caused many fragments (Zhou et al., 2005). Therefore, a large number of linear traces on the failure surface after the quasi-static experiment are as shown in Fig. 10(c) and (d). But after the dynamic experiment, in Fig. 10(e) and (f), the number of protrusions on the failure surface was increased. Additionally, the GO-epoxy had more protrusions on the failure surface under quasi-static or dynamic experiments, which provides more evidence that the addition of GO might limit the motion of the molecular chains. The possible reasons for the formation of protrusions are the large number of cross-linking points and aggregation areas, which caused by hydrogen bonding (Zhang et al., 2019). The polymer cross-linking network of epoxy is strengthened and inhibits the movement of molecular chains. The results of some atomic simulation techniques show that the modulus of epoxy depends not only on the stiffness of the molecule, but also on the intermolecular forces and the 
(a)

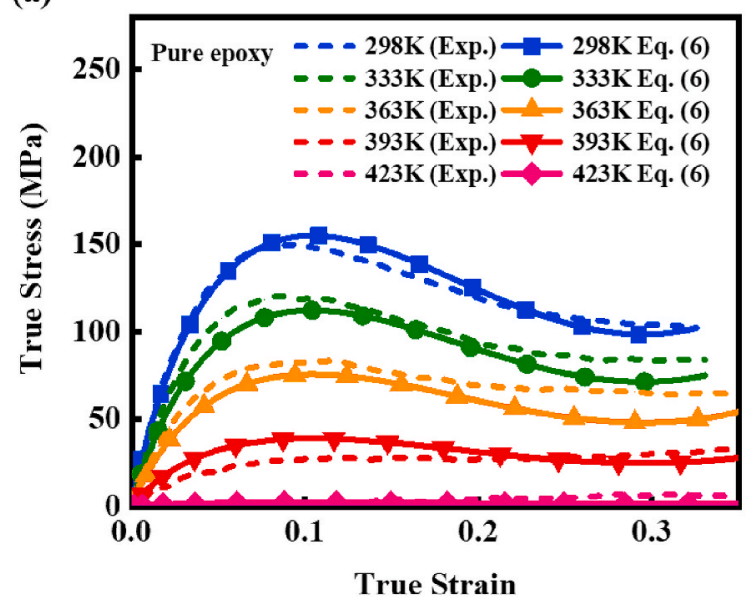

(b)

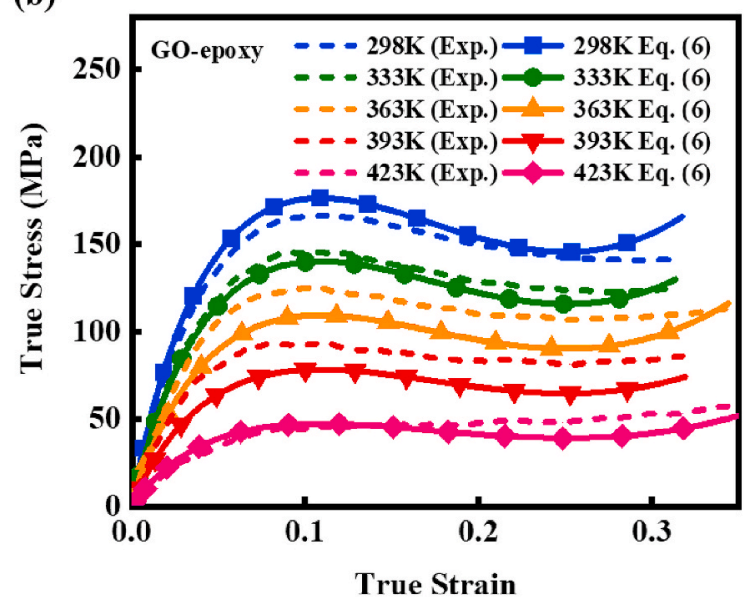

(c)

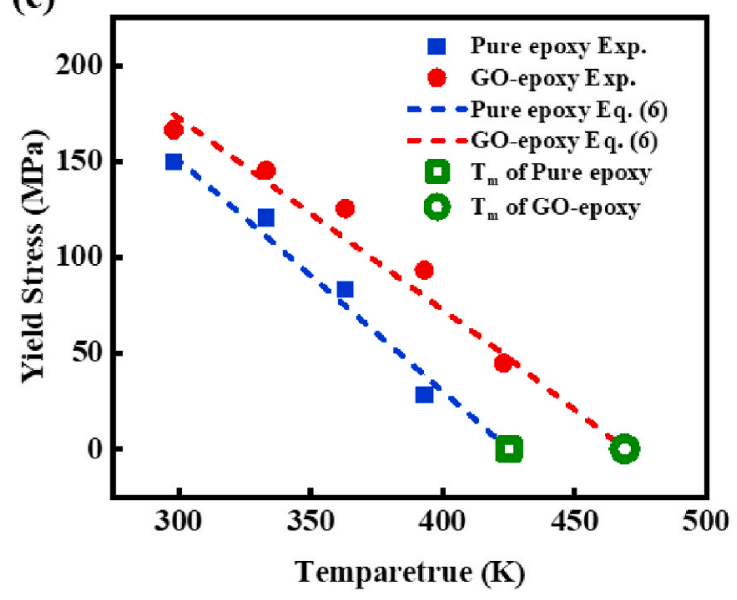

Fig. 8. Temperature-dependent constitutive equation and experiment curves of (a) pure epoxy (b) GO-epoxy and (c) yield stress as a function of temperature.

Table 2

Material parameters of the constitutive model in Eq. (6).

\begin{tabular}{llllllll}
\hline Parameters & $\begin{array}{l}E_{0} \\
(\mathrm{GPa})\end{array}$ & $\begin{array}{l}\alpha \\
(\mathrm{GPa})\end{array}$ & $\begin{array}{l}\beta \\
(\mathrm{GPa})\end{array}$ & $\begin{array}{l}\lambda \\
(1)\end{array}$ & $\begin{array}{l}E_{1} \\
(\mathrm{MPa})\end{array}$ & $\begin{array}{l}\theta \\
(\mu \mathrm{s})\end{array}$ & $\begin{array}{l}T_{m} \\
(\mathrm{~K})\end{array}$ \\
\hline Pure Epoxy & 4.59 & 25.62 & 26.48 & 1.655 & 813 & 6.73 & 425 \\
GO-Epoxy & 4.95 & 31.99 & 31.83 & 1.673 & 1069 & 7.44 & 469 \\
\hline
\end{tabular}

(a)

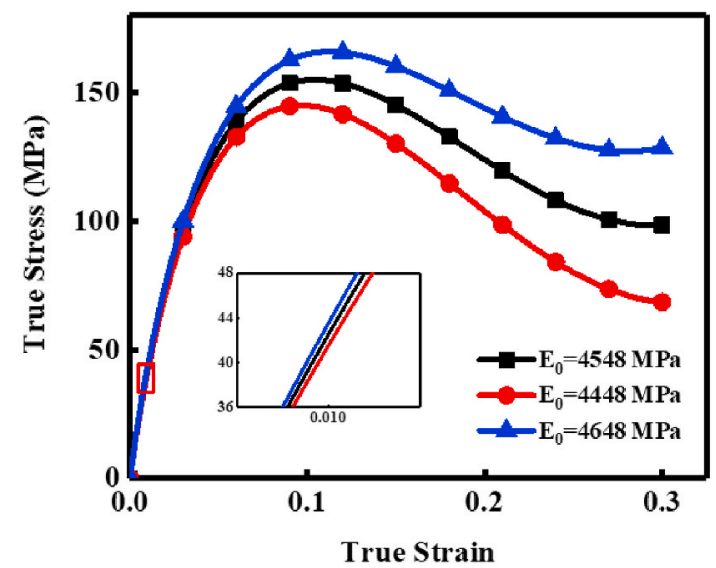

structural system of the molecular chain (Zhang et al., 2017). The research has indicated that the cross-linking strengthening effect of hydrogen bonds in some types of epoxy resins even improves both strength and ductility of the epoxy (Zhang et al., 2019). The GO fillers improved the mechanical properties and high temperature stability of the epoxy by strengthening the intermolecular force and molecular chain crosslinking of the epoxy.

Fig. 9. Stress-strain curves with the effect of (a) initial elastic modulus $E_{0}$ and (b) elastic constant $E_{1}$. 
(a)

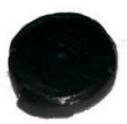

GO-epoxy

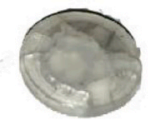

Pure epoxy (b)

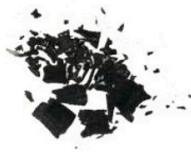

GO-epoxy

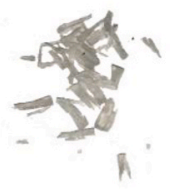

Pure epoxy (c) Pure epoxy (quasi-static)

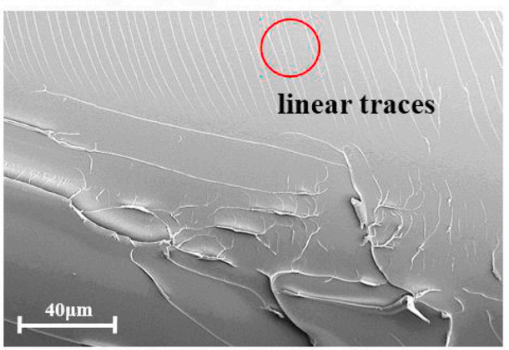

(f) GO-epoxy (dynamic)

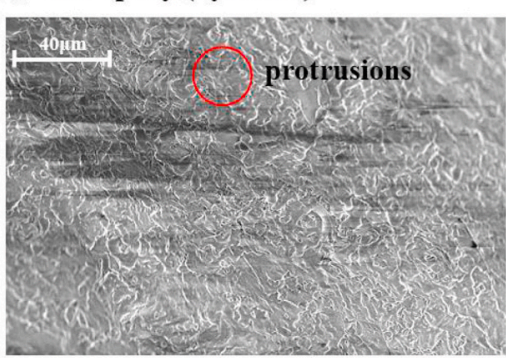

(d) GO-epoxy (quasi-static)

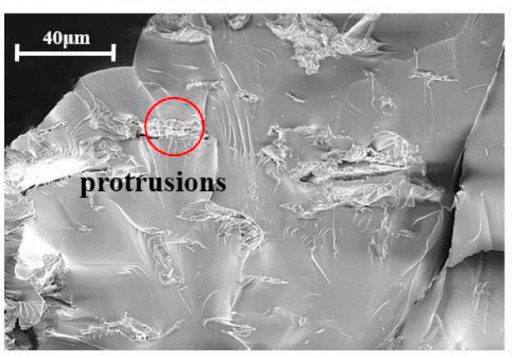

(e) Pure epoxy (dynamic)

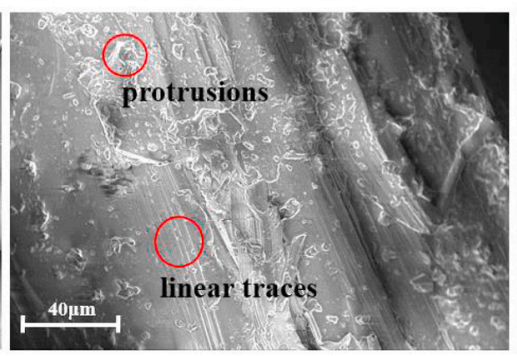

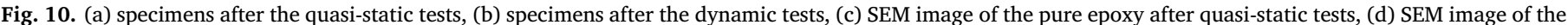
GO-epoxy after quasi-static tests, (e) SEM image of the pure epoxy after dynamic tests, (f) SEM image of the GO-epoxy after dynamic tests.

\section{Conclusions}

A series of experiments were conducted to compare the dynamic behavior $\left(5000 \mathrm{~s}^{-1}\right)$ of GO-epoxy and pure epoxy from room temperature to $423 \mathrm{~K}$. A high temperature furnace having an observation window was used to heat the specimens and to observe the dynamic process of different specimens. The results indicate that the addition of GO significantly improved the mechanical properties and temperature stability of epoxy. Additionally, GO increased the strain rate sensitivity and strain energy density of epoxy, and restrained the stress-softening phenomenon of epoxy. The thermal stability of GO-epoxy was better than that of pure epoxy, and the stress drop of these epoxies gradually decreased and eventually diminished as the temperature increases. The difference between the stress softening and thermal softening behaviors of GO-epoxy and pure epoxy indicates that GO restricted the freedom of epoxy's molecular chains. Moreover, the temperature equivalent strain rates of pure epoxy and GO-epoxy differ by an order of magnitude. Accurate DIC analysis results indicate that strain fields were consistent with the experimental data. The higher the temperature, the more the improvement of GO-epoxy in impact resistance and temperature stability is than that of pure epoxy.

A modified constitutive equation with temperature variation term was introduced to further illustrate the deformation mechanisms of materials. The calculated result agreed well with the experimental data at different temperatures. The microscopic morphology of the failure surface demonstrates the existence of interfacial interaction between GO and epoxy. The strong interfacial action of GO increased the number of micro cracks on the failure surface and the hydrogen bond formed by the addition of GO strengthens the crosslinking network of epoxy. The above was the main reason why GO-epoxy has good mechanical properties and thermal stability in this work. This work could be regarded as a reference in designing high-performance lightweight anti-collision composites to meet the requirement of thermal environment.

\section{CRediT authorship contribution statement}

Yu Qiao: Data curation, Investigation, Formal analysis, Writing original draft, Writing - review \& editing. Pengfei Wang: Conceptualization, Methodology, Writing - review \& editing. Xiao Xue:
Writing - review \& editing. Mao Liu: Validation. Songlin Xu: Supervision, Project administration.

\section{Declaration of competing interest}

The authors declare that they have no known competing financial interests or personal relationships that could have appeared to influence the work reported in this paper.

\section{Acknowledgments}

This work was supported by the National Natural Science Foundation of China (Grant Nos. 11872361, 11672286). This work was also supported by the Fundamental Research Funds for the Central Universities (WK2090050040, WK 2480000003) and visiting scholar program sponsored by China Scholarship Council.

\section{Appendix A. Supplementary data}

Supplementary data to this article can be found online at https:// doi.org/10.1016/j.mechmat.2020.103593.

\section{References}

Acar, A., Colak, O., Correia, J.P.M., Ahzi, S., 2018. Cooperative-VBO model for polymer/ graphene nanocomposites. Mech. Mater. 125, 1-13.

Adak, N.C., Chhetri, S., Kuila, T., Murmu, N.C., Samanta, P., Lee, J.H., 2018. Effects of hydrazine reduced graphene oxide on the inter-laminar fracture toughness of woven carbon fiber/epoxy composite. Compos. B Eng. 149, 22-30.

Arash, B., Exner, W., Rolfes, R., 2019. A viscoelastic damage model for nanoparticle/ epoxy nanocomposites at finite strain: a multiscale approach. J. Mech. Phys. Solid. $128,162-180$.

Ávila, A.F., Neto, A.S., Nascimento Junior, H., 2011. Hybrid nanocomposites for midrange ballistic protection. Int. J. Impact Eng. 38, 669-676.

Barai, P., Weng, G.J., 2011. A theory of plasticity for carbon nanotube reinforced composites. Int. J. Plast. 27, 539-559.

Chabot, V., Higgins, D., Yu, A., Xiao, X., Chen, Z., Zhang, J., 2014. A review of graphene and graphene oxide sponge: material synthesis and applications to energy and the environment. Energy Environ. Sci. 7, 1564.

Chen, J., Zhao, D., Jin, X., Wang, C., Wang, D., Ge, H., 2014. Modifying glass fibers with graphene oxide: towards high-performance polymer composites. Compos. Sci. Technol. 97, 41-45.

Chen, W., Song, B., 2011. Split Hopkinson (Kolsky) Bar-Design, Testing and Applications. Springer, New York. 
Cui, T., Mukherjee, S., Cao, C., Sudeep, P.M., Tam, J., Ajayan, P.M., Singh, C.V., Sun, Y., Filleter, T., 2018. Effect of lattice stacking orientation and local thickness variation on the mechanical behavior of few layer graphene oxide. Carbon 136, 168-175.

Dépinoy, S., Massart, T.J., Godet, S., Pardoen, T., 2019. On the mode I toughness of adhesive bonds exhibiting strain-softening and re-hardening. Int. J. Solid Struct. 162, $1-13$.

Fu, R.R., Weiss, B.P., Lima, E.A., Harrison, R.J., Bai, X.N., Desch, S.J., Ebel, D.S., Suavet, C., Wang, H., Glenn, D., Le Sage, D., Kasama, T., Walsworth, R.L., Kuan, A.T., 2014. Paleomagnetism. Solar nebula magnetic fields recorded in the Semarkona meteorite. Science 346, 1089-1092.

Gao, G., Li, Y., 2016. Dynamic behavior of a woven glass-fiber-reinforced polymer composite at high strain rates and its dynamic constitutive relationship. Mech. Adv. Mater. Struct. 24, 1086-1093.

Gogoi, P., Boruah, R., Dolui, S.K., 2015. Jatropha curcas oil based alkyd/epoxy/graphene oxide (GO) bionanocomposites: effect of GO on curing, mechanical and thermal properties. Prog. Org. Coating 84, 128-135.

Gómez-del Río, T., Rodríguez, J., 2012. Compression yielding of epoxy: strain rate and temperature effect. Mater. Des. 35, 369-373.

Green, A.E., Rivlin, R.S., 1957. The Mechanics of Non-linear Materials with Memory. Archive for Rational Mechanics and Analysis.

Guo, T., Chen, X., Su, L., Li, C., Huang, X., Tang, X.-Z., 2019. Stretched graphene nanosheets formed the "obstacle walls" in melamine sponge towards effective electromagnetic interference shielding applications. Mater. Des. 182.

Kapnistos, M., Lang, M., Vlassopoulos, D., Pyckhout-Hintzen, W., Richter, D., Cho, D., Chang, T., Rubinstein, M., 2008. Unexpected power-law stress relaxation of entangled ring polymers. Nat. Mater. 7, 997-1002.

Khan, A.S., Wilgeroth, J., Balzer, J., Proud, W.G., 2017. Comparison of epoxy-based encapsulating materials over temperature and strain rate. AIP Conference Proceedings 1793, 110017.

Liao, Z., Yao, X., Zhang, L., Hossain, M., Wang, J., Zang, S., 2019. Temperature and strain rate dependent large tensile deformation and tensile failure behavior of transparent polyurethane at intermediate strain rates. Int. J. Impact Eng. 129, 152-167.

Liu, J., Suo, T., Fan, Y., Li, J., Zhou, F., Li, Y., 2018. Dynamic mechanical responses of ultrafine-grained IF steel over a wide range of temperatures. Int J Appl Mech 10, 1850044 .

Mulliken, A.D., Boyce, M.C., 2006. Mechanics of the rate-dependent elastic-plastic deformation of glassy polymers from low to high strain rates. Int. J. Solid Struct. 43, 1331-1356.

O'Masta, M.R., Russell, B.P., Deshpande, V.S., 2017. An exploration of the ballistic resistance of multilayer graphene polymer composites. Extreme Mech Lett 11, 49-58.

Pathak, A.K., Borah, M., Gupta, A., Yokozeki, T., Dhakate, S.R., 2016. Improved mechanical properties of carbon fiber/graphene oxide-epoxy hybrid composites. Compos. Sci. Technol. 135, 28-38.

Payeganeh, G.H., Ashenai Ghasemi, F., Malekzadeh, K., 2010. Dynamic response of fiber-metal laminates (FMLs) subjected to low-velocity impact. Thin-Walled Struct. 48, $62-70$.

Sheinerman, A.G., Morozov, N.F., Gutkin, M.Y., 2019. Effect of grain boundary sliding on fracture toughness of ceramic/graphene composites. Mech. Mater. 137.

Song, B., Sanborn, B., 2018. Relationship of compressive stress-strain response of engineering materials obtained at constant engineering and true strain rates. Int. J. Impact Eng. 119, 40-44.

Tian, H., Zhang, B., Li, Q.M., 2019. Ballistic response of hexagonal boron nitride monolayer under impact of a nano-projectile. Mech. Mater. 133, 1-12.
Treutenaere, S., Lauro, F., Bennani, B., Haugou, G., Matsumoto, T., Mottola, E., 2017. Constitutive modelling of the strain-rate dependency of fabric reinforced polymers. Int. J. Impact Eng. 108, 361-369.

Wan, Y., Tang, L., Gong, L., Yan, D., Li, Y., Wu, L., Jiang, J., Lai, G., 2014. Grafting of epoxy chains onto graphene oxide for epoxy composites with improved mechanical and thermal properties. Carbon 69, 467-480.

Wang, L., Zhou, F., Sun, Z., Wang, Y., Shi, S., 2010. Studies on rate-dependent macrodamage evolution of materials at high strain rates. Int. J. Damage Mech. 19, 805-820.

Wang, P., Xu, S., Li, Z., Yang, J., Zhang, C., Zheng, H., Hu, S., 2015. Experimental investigation on the strain-rate effect and inertia effect of closed-cell aluminum foam subjected to dynamic loading. Mater. Sci. Eng. 620, 253-261.

Wang, P., Xu, S., Li, Z., Yang, J., Zheng, H., Hu, S., 2014. Temperature effects on the mechanical behavior of aluminum foam under dynamic loading. Mater. Sci. Eng. 599, 174-179.

Wang, P., Yang, J., Liu, W., Tang, X., Zhao, K., Lu, X., Xu, S., 2017. Tunable crack propagation behavior in carbon fiber reinforced plastic laminates with polydopamine and graphene oxide treated fibers. Mater. Des. 113, 68-75.

Wang, P., Yang, J., Zhang, X., Zhang, H., Zhou, L., Liu, W., Zheng, H., Zhang, M., Shang, J., Xu, S., 2019. Dynamic behavior of carbon nanofiber-modified epoxy with the effect of polydopamine-coated interface. Mech. Adv. Mater. Struct. 1-13.

Ward, I.M., Pinnock, P.R., 1966. The mechanical properties of solid polymers. Br. J. Appl. Phys. 17.

Wei, Y., Hu, X., Jiang, Q., Sun, Z., Wang, P., Qiu, Y., Liu, W., 2018. Influence of graphene oxide with different oxidation levels on the properties of epoxy composites. Compos. Sci. Technol. 161, 74-84.

Williamson, D.M., Siviour, C.R., Proud, W.G., Palmer, S.J.P., Govier, R., Ellis, K., Blackwell, P., Leppard, C., 2008. Temperature-time response of a polymer bonded explosive in compression (EDC37). J. Phys. D Appl. Phys. 41.

Xia, X., Zhong, Z., Weng, G.J., 2017. Maxwell-Wagner-Sillars mechanism in the frequency dependence of electrical conductivity and dielectric permittivity of graphenepolymer nanocomposites. Mech. Mater. 109, 42-50.

Xiao, R., Nguyen, T.D., 2015. An effective temperature theory for the nonequilibrium behavior of amorphous polymers. J. Mech. Phys. Solid. 82, 62-81.

Yan, W., Fang, L., Heuchel, M., Kratz, K., Lendlein, A., 2015. Modeling of stress relaxation of a semi-crystalline multiblock copolymer and its deformation behavior. Clin. Hemorheol. Microcirc. 60, 109-120.

Ye, T., Xu, Y., Ren, J., 2019. Effects of SiC particle size on mechanical properties of SiC particle reinforced aluminum metal matrix composite. Mater. Sci. Eng. 753, 146-155.

Zhang, P., Kan, L., Zhang, X., Li, R., Qiu, C., Ma, N., Wei, H., 2019. Supramolecularly toughened and elastic epoxy resins by grafting 2-ureido-4[1H]-pyrimidone moieties on the side chain. Eur. Polym. J. 116, 126-133.

Zhang, W., Qing, Y., Zhong, W., Sui, G., Yang, X., 2017. Mechanism of modulus improvement for epoxy resin matrices: a molecular dynamics simulation. React. Funct. Polym. 111, 60-67.

Zhang, X., Wang, P., Sun, D., Li, X., An, J., Yu, T.X., Yang, E.-H., Yang, J., 2020. Dynamic plastic deformation and failure mechanisms of individual microcapsule and its polymeric composites. J. Mech. Phys. Solid. 139.

Zhou, F., Molinari, J., Shioya, T., 2005. A rate-dependent cohesive model for simulating dynamic crack propagation in brittle materials. Eng. Fract. Mech. 72, 1383-1410.

Zhou, G., Hu, S., Fu, Y., 2010. SHPB technology for measuring high temperature dynamic mechanical properties of materials. J. Exp. Mech. 9-15 (In Chinese).

Zhou, L., Xu, S., Shan, J., Liu, Y., Wang, P., 2018. Heterogeneity in deformation of granite under dynamic combined compression/shear loading. Mech. Mater. 123, 1-18. 